\title{
Research on Vertical Stiffener of Box Strengthen-joint Region Connection for Weak Axis of I-section Column
}

\author{
Shun Zhang ${ }^{1, a}$, Linfeng $\mathrm{Lu}^{1, \mathrm{~b}}$, Lulu Wang ${ }^{1, \mathrm{c}}$ \\ ${ }^{1}$ Chang'an University School of Civil Engineering, Xi'an China \\ a3793089@qq.com, b54llf@163.com, c245401179@qq.com
}

\begin{abstract}
Keywords: weak axis; ductility; vertical stiffener; hysteretic property;
Abstract. The weak axis of I-section column welded the vertical stiffener to simulate the form of strong axis connection. The seismic behavior of joint region and the affections on the ultimate bearing capacity of beam by changing the thickness of skin panel have been analyzed. The hysteretic behavior of joint region, the flexural bearing capacity of beam, distribution of the stress across the weld at beam flange, ductility and energy dissipation capacity have been discussed. The addition of vertical stiffener can increase the stiffness by $7 \%-11 \%$ and the energy dissipation capacity can be increased by $15 \%$. All of the models' relative ultimate rotation angle of beam-column joint are close to $0.03 \mathrm{rad}$. The weak axis of I-section column under strong axis affections which ductility factors are greater than 2 .The weld edge stress at beam flange was reduced by $4 \%-6 \%$.
\end{abstract}

\section{Introduction}

The h-shaped section is one of the sections of steel structure, which is widely used in various kinds of projects. Because of the load conditions is different between the two major axes of h-shaped column, the stress distribution, flexural bearing and seismic energy dissipation capacities vary greatly in rotating around the two different axes. The weak axis of beam-column connection just like the strong axis were ubiquity in practical engineering. Now the domestic and foreign researches are mainly focused on the strong axis, and have formed a series of mature theoretical system, by contrast, there is a lack of experiments and theory study for weak axis. Column in two perpendicular directions connected beam should use box column stipulated by current Chinese "Seismic design code for buildings"(GB50011-2010) [1], chapter 8.3.4. If the connection in weak axis direction has well mechanical performance, then partial substitution of h-shaped column for box column, thus cutting the costs. Inventing new kind of I-section column connection in the weak axis can improve the economic efficiency for engineering, make it used reasonably and safely, and adjust to the needs of our national economic construction.

The joint region is the key part of connecting and transferring force in frame structure. If the integral rigidity of joint region is feeble, great shear deformation can form when the earthquake happens. But if it is too large, rotational deformation capacity and ductility will go down, which is unfavorable to seismic resistance and energy dissipation, and the same is true for the weak axis. About weak axis connecting, the recommended procedures of our national industry standards is shown in Fig.1 (hereinafter referred to as traditional connection), this practice cannot meet the demands of strong joint and weak unit very well. The new type of connection practice is shown in Fig.2 (hereinafter referred to as new connection). According to the literature [2], the new connection under external force made the stress across the weld at flange of beam concentrates on the edge, which lead to the uneven stress of welding seam.

This research is based on the concept of new connection in weak axis of h-shaped column. Considering the affections of strong axis, the situation in welding the vertical stiffener in the middle of transverse stiffener of joint region were simulated by finite element analysis software. By comprehensive correlation of theoretical and simulation results, the paper analyzes the influence of mechanical properties in joint region when welded the vertical stiffener or not. And strength, deformation, ductility, stress-strain curve and the failure mode were discussed, aiming at making suggestions for improvement and providing a reference for engineering design. 


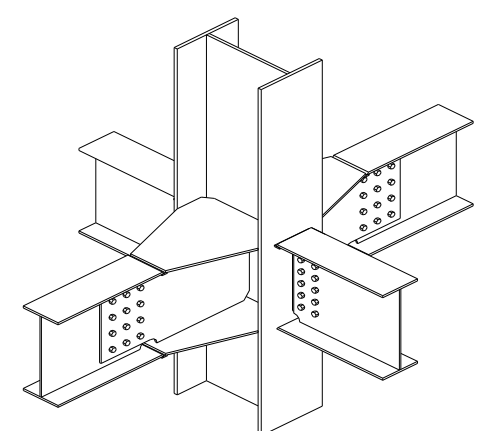

Fig1. Tradition joint of weak axis

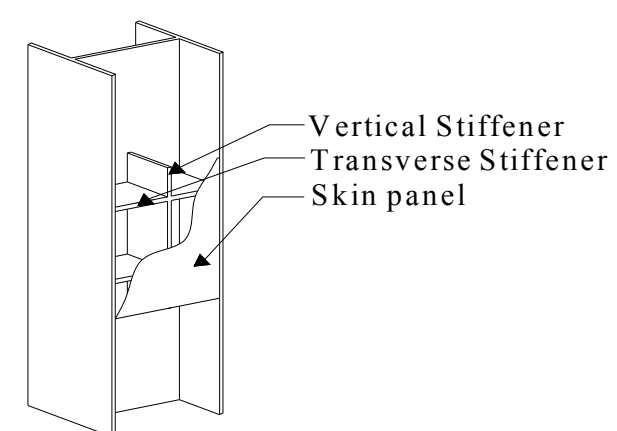

Fig2. Modified joint of weak axis

\section{Finite Element Simulation}

The new type of weak axial connection at the outer margin of the column flange welded two steel plates which parallel to column web, hereinafter referred to as skin panel. And corresponding to the upper flange and lower flange of I-beam were planted the lateral stiffeners within the skin panels, as an alternative to the old wedge stiffeners load-transferred mode. In order to verify the mechanical behavior of the weak axis simulating strong axis after welded vertical stiffeners, the paper designed five sets of finite element models.

Model Design. Under horizontal load, the inflection point exists in beam and column of steel frame structure, cutting off at the inflection point can obtain substructure. Taking inflection point as the coupling point, and load was applied at this point.

The Lab. of Structure Engineering and Earthquake Resistance in Chang'an University has done a series of experimental studies on new type of weak axis connection, the beam and column dimensions are taken from the experiment that described in literature [2]. Specimens of beam and column dimensions are shown in Table 1. The experiment in the literature provides a good data to establish finite element model. H-shaped steel columns is $3 \mathrm{~m}$ high, h-shaped steel beam has a length of $1.5 \mathrm{~m}$. The steel material properties are dependent on the test of specimen material and summarized in Table 2 .

Table.1

Dimensions of specimen sections

\begin{tabular}{|c|c|c|c|c|c|}
\hline $\begin{array}{l}\text { Specimen } \\
\text { designation }\end{array}$ & $\begin{array}{l}\text { Column section size } \\
(\mathrm{mm})\end{array}$ & $\begin{array}{c}\text { Beam section size } \\
(\mathrm{mm})\end{array}$ & $\begin{array}{c}\text { Skin panel } \\
(\mathrm{mm})\end{array}$ & $\begin{array}{c}\text { Vertical stiffener } \\
(\mathrm{mm})\end{array}$ & Strong axis \\
\hline JD-1 & HW $300 \times 300 \times 10 \times 15$ & $\mathrm{HN} 350 \times 175 \times 7 \times 11$ & 16 & 0 & No \\
\hline JD-2 & HW $300 \times 300 \times 10 \times 15$ & $\mathrm{HN} 350 \times 175 \times 7 \times 11$ & 16 & 12 & No \\
\hline JD-3 & HW $300 \times 300 \times 10 \times 15$ & $\mathrm{HN} 350 \times 175 \times 7 \times 11$ & 16 & 0 & Yes \\
\hline JD-4 & HW $300 \times 300 \times 10 \times 15$ & $\mathrm{HN} 350 \times 175 \times 7 \times 11$ & 12 & 12 & Yes \\
\hline JD-5 & HW $300 \times 300 \times 10 \times 15$ & $\mathrm{HN} 350 \times 175 \times 7 \times 11$ & 16 & 12 & Yes \\
\hline
\end{tabular}

Finite Element Modeling. ABAQUS has a strong nonlinear analysis capabilities, both on linear-elastic problems and contact problems in complex multi-component. ABAQUS also shows higher accuracy and speed of operation. Use ABAQUS to establish three-dimensional solid model, bilinear kinematic hardening (BKIN) can reflect the Bauschinger effect of steel better, but only in a small strain to get the satisfactory result. So consider using the mixed hardening criterion which is composed of equivalent strengthen and kinematic hardening to simulate cyclic plasticity flow of steel. The yield criterion depends on the Von Mises yield criterion which is suitable for metallic materials. Considering the problems of contact, large deformation and computation time, this paper selects C3D8I element (secondary non-coordinated element). Uses Tie to simulate welding connections.

Loading System. Using story drift angle to control the shift of beam end, this method recommended by the American Institute of Steel Construction (AISC). According to the literature [3], use angle $\theta_{\mathrm{b}}$ of beam end to instead of story drift angle $\theta_{\mathrm{c}}, L$ represents the beam's length. The concentrated load is applied to the top of column and the load-displacement cyclic datum calculated by Eq. 1 is shown in Table 3. The axial compression ratio is 0.3 and each turn is 2-3 cycles of loading. 
Table.2

Main properties of specimen materials

\begin{tabular}{ccccc}
\hline $\begin{array}{c}\text { Steel plate } \\
\text { thickness } \\
(\mathrm{mm})\end{array}$ & $\begin{array}{c}\text { Yielding } \\
\text { strength } \\
\mathrm{f}_{\mathrm{y}}\left(\mathrm{N} / \mathrm{mm}^{2}\right)\end{array}$ & $\begin{array}{c}\text { Tensile } \\
\text { strength } \\
\mathrm{f}_{\mathrm{u}}\left(\mathrm{N} / \mathrm{mm}^{2}\right)\end{array}$ & $\begin{array}{c}\text { Elastic } \\
\text { modulus } \\
\mathrm{E}(\mathrm{Mpa})\end{array}$ & $\begin{array}{c}\text { Elongation } \\
\delta(\%)\end{array}$ \\
\hline 7 & 332.2 & 468.0 & 202324 & 27.8 \\
10 & 278.7 & 460.6 & 206162 & 28.4 \\
11 & 295.5 & 443.2 & 204381 & 29.1 \\
12 & 281.5 & 463.6 & 203648 & 29.0 \\
15 & 253.1 & 472.1 & 208780 & 27.1 \\
16 & 275.3 & 465.7 & 203972 & 27.6 \\
\hline
\end{tabular}

Cyclic loading system:

$$
\Delta=L \times \theta_{b}=1500 \times \theta_{b}
$$

Table.3

Cyclic loading programs of specimens

\begin{tabular}{cccc}
\hline $\begin{array}{c}\text { Load } \\
\text { grade }\end{array}$ & $\begin{array}{c}\text { Drift angle } \\
\text { (radians) }\end{array}$ & $\begin{array}{c}\text { Displacement } \\
(\mathrm{mm})\end{array}$ & $\begin{array}{c}\text { Cycle } \\
\text { index }\end{array}$ \\
\hline 1 & 0.00375 & \pm 5.63 & 6 \\
2 & 0.005 & \pm 7.5 & 6 \\
3 & 0.0075 & \pm 11.25 & 6 \\
4 & 0.01 & \pm 15 & 4 \\
5 & 0.015 & \pm 22.5 & 2 \\
6 & 0.02 & \pm 30 & 2 \\
7 & 0.03 & \pm 45 & 2 \\
8 & 0.04 & \pm 60 & 2 \\
9 & 0.05 & \pm 75 & 2 \\
10 & 0.055 & \pm 82.5 & 2 \\
\hline
\end{tabular}

\section{The Computer Simulation Results and Analysis}

Most of beam-column joints belongs to semi-rigid connections which is between the fully rigid connections and ideal hinge connections in actual engineering. This paper selects the general moment method introduced in the literature [4] to determine the yield point. [Through the origin $\mathrm{O}$ making tangent of $P-\triangle$ curve intersect a line that parallel to axis $\mathrm{X}$ and across the maximum load point $\mathrm{B}$ at point $\mathrm{A}$. Over A point making a vertical line intersect the curve at point $\mathrm{C}$. Then connects $\mathrm{OC}$ and extends to the horizontal line $\mathrm{AB}$, and the intersection point is denoted by $\mathrm{D}$. Over $\mathrm{D}$ point making perpendicular line cross the curve at point E, E point is just the yield point, shown in Fig.3.]

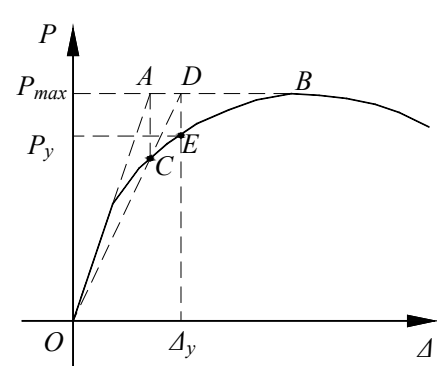

Fig.3 Determination for yield point of specimen

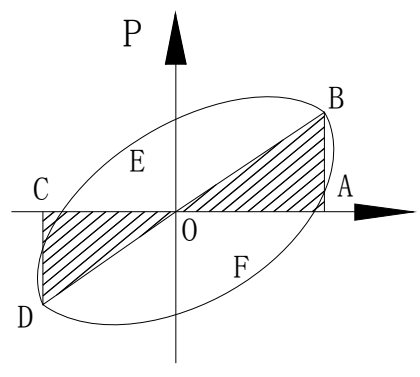

Fig.4 Graphic calculation

Specimen Failure. $P_{\max }$ is the ultimate load of the specimen, $\Delta_{\max }$ is the displacement while the $P_{\max }$ occurred. The general definition of failure load $P_{\mathrm{u}}=0.85 P_{\max }$. Its corresponding displacement $\Delta_{\mathrm{u}}$ is called the limit displacement. $\Delta_{\mathrm{y}}$ is yield displacement corresponding to the yield load $P_{\mathrm{y}}$, and its calculation method is described above.

Table 4 shows that, the ultimate bearing capacity of the weak axis direction makes little differences among 5 sets of model, and all the differences are less than $4.5 \%$. It is easy to see that the model adding vertical stiffeners has increased the yield strength in some degree, about $7 \%$ to $11 \%$, but increased range is limited. Because the stiffness of joint region without vertical stiffener is small, the load of model 1 and 3 have not dropped to 0.85 times of the ultimate load at the end of this cycle, so this situation will not be discussed.

Table.4

Simulation results

\begin{tabular}{ccccccccc}
\hline $\begin{array}{c}\text { Specimen } \\
\text { designation }\end{array}$ & \multicolumn{2}{c}{ Yielding strength } & & \multicolumn{2}{c}{ Ultimate strength } & & \multicolumn{2}{c}{ Failure strength } \\
\cline { 2 - 3 } \cline { 7 - 8 } & $P_{\mathrm{y}}(\mathrm{kN})$ & $\Delta_{\mathrm{y}}(\mathrm{mm})$ & & $P_{\max }(\mathrm{kN})$ & $\Delta_{\max }(\mathrm{mm})$ & & $P_{\mathrm{u}}(\mathrm{kN})$ & $\Delta_{\mathrm{u}}(\mathrm{mm})$ \\
\hline JD-1 & 183.11 & 23.77 & & 211.6 & 44.3 & & 179.9 & - \\
JD-2 & 194.70 & 19.98 & & 214.4 & 44.6 & & 182.3 & 77.3 \\
JD-3 & 176.73 & 25.42 & & 211.0 & 59.2 & & 179.3 & - \\
JD-4 & 196.35 & 21.36 & & 220.2 & 44.9 & & 187.2 & 75.6 \\
JD-5 & 196.08 & 21.33 & & 219.7 & 44.7 & & 186.7 & 75.8 \\
\hline
\end{tabular}


P- $\boldsymbol{\Delta}$ Hysteresis Curve of Node Model. The hysteresis curves of different models are shown in Fig.5. The hysteresis curve of JD-1 present a shape of flat and long. When the load up to maximum, after that the stiffness degradation tend to slow, and shows flexibility. Through comparing the curve of JD-1 with JD-2, the rigidity of welded vertical stiffeners are increased $10.2 \%$, but ultimate strength only increased $1.35 \%$. Therefore, the influence of vertical stiffeners on ultimate bearing capacity can be neglected.

Due to the influence of strong axis, the joint region has strong constraint and reduced the rotation capacity. When buckling or yield appears in one major axis, the stiffness and strength of the other axis will be reduced. The hysteresis curve in JD-3 of weak axis direction showed that this joint region is more flexible than JD-5. JD-3 compared to JD-1, the displacement of peak load is increased by nearly $33.7 \%$. JD-5 compared to JD-1, the displacement of peak load, it has only increased by $1.3 \%$. The conclusion can be made that the vertical stiffeners can improve the flexural stiffness of the beam weak axis, reduces the effect of strong axis, and protect the joint region not to incur excessive shear deformation under the seismic load.

From the Fig.5 (d, e) and Fig.6 (b) we can see that the skeleton curve of $12 \mathrm{~mm}$ thick skin panel contrasted with $16 \mathrm{~mm}$ thick are almost coincident. The results indicate that decreased thickness of the skin panel has little effect on ultimate bearing capacity.

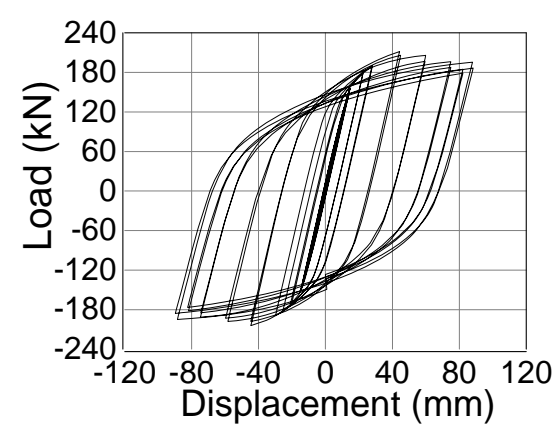

(a) JD-1

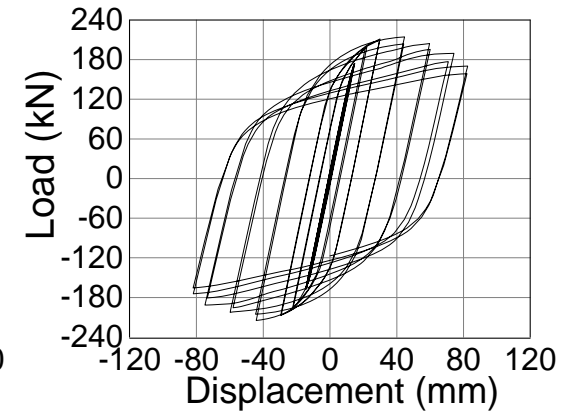

(b) JD-2

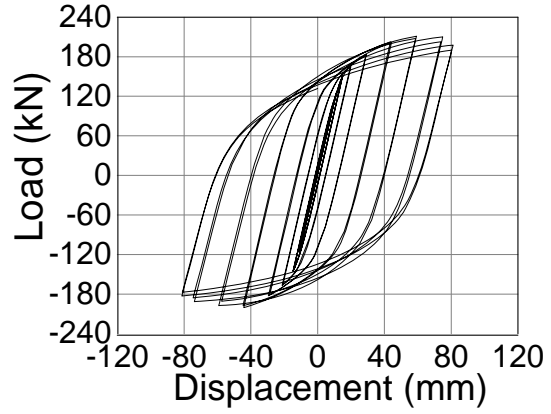

(c) JD-3

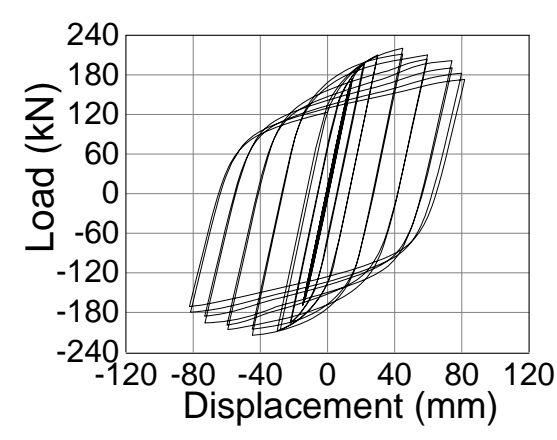

(d) JD-4

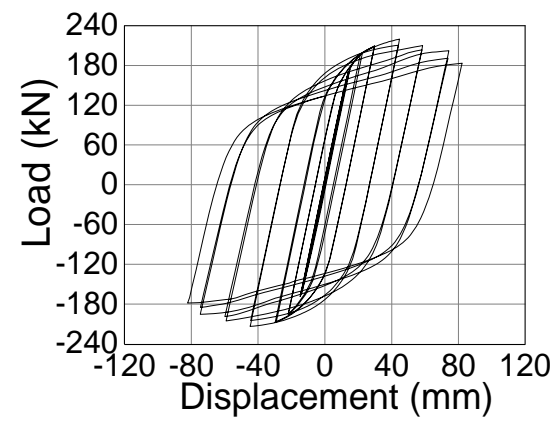

(e) JD-5

Fig.5 Hysteresis loops of specimen

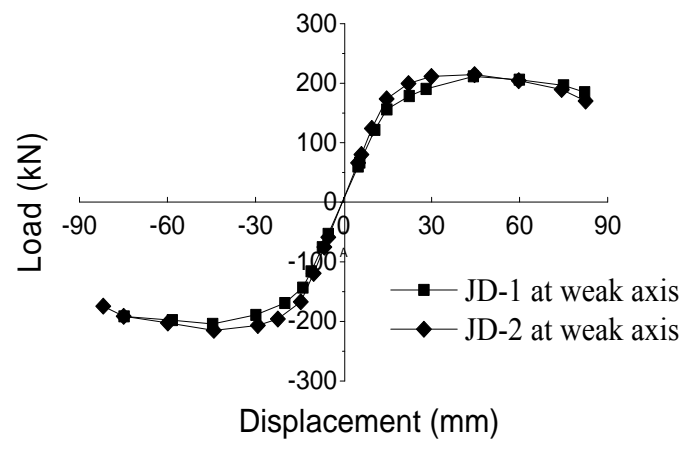

(a)

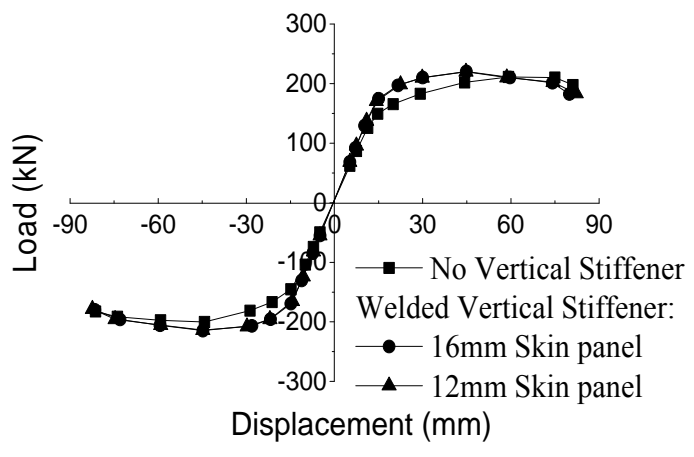

(b)

Fig.6 Comparison of skeleton hysteresis curve 


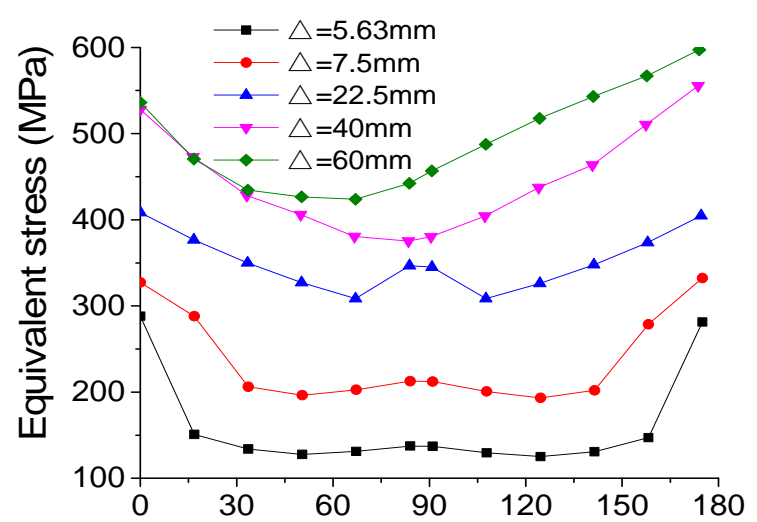

Stress across the weld at flange of beam $(\mathrm{mm})$

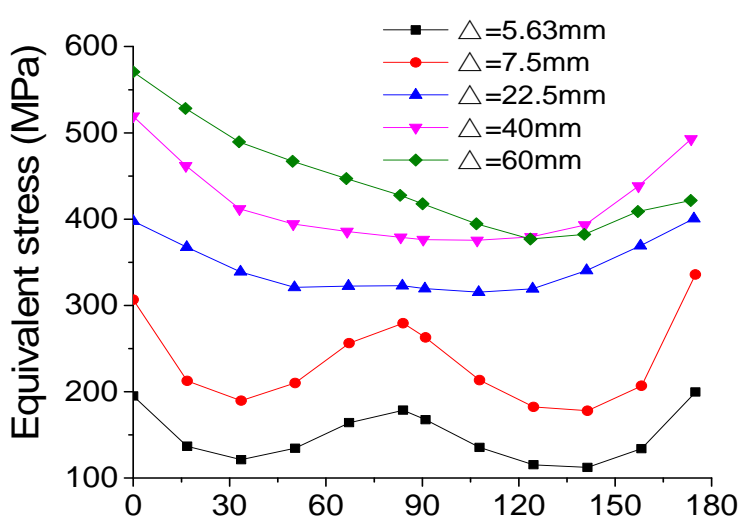

Stress across the weld at flange of beam $(\mathrm{mm})$

(a) JD-3

(b) JD-5

Fig.7 Distribution of the stress across the weld at flange of beam

Ductility and Energy Dissipation. The ratio of the yielding angle $\theta_{\mathrm{u}}$ to the failure angle $\theta_{\mathrm{y}}$ is the angle ductility ratio $\mu_{\theta}\left(\mu_{\theta}=\theta_{\mathrm{u}} / \theta_{\mathrm{y}}\right)$. And the displacement ductility ratio $\mu=\Delta_{\mathrm{u}} / \Delta_{\mathrm{y}}$. According to the envelope diagram of load-displacement curve can calculate the viscous damping coefficient $h_{\mathrm{e}}$ by Eq. 2 and energy dissipation coefficient $E$ by Eq.3, which is shown in Fig. 4 and Table.5.

$$
\begin{aligned}
& h_{e}=\frac{1}{2 \pi} \bullet \frac{\text { Hysteretic Curve Envelope Area }(B E D+B F D)}{\text { Triangle Area }(A O B+C O D)} \\
& E=2 \pi h_{e}
\end{aligned}
$$

Table.5

Ductility and energy dissipation indexes of specimens

\begin{tabular}{ccccccc}
\hline Models & $\theta_{y}(\mathrm{rad})$ & $\theta_{u}(\mathrm{rad})$ & $\mu_{\theta}$ & $\mu$ & $h_{e}$ & $E$ \\
\hline JD-1 & 0.014 & 0.0268 & 1.914 & 1.86 & 0.359 & 2.26 \\
JD-2 & 0.012 & 0.0270 & 2.250 & 2.23 & 0.425 & 2.67 \\
JD-3 & 0.015 & 0.0359 & 2.393 & 2.33 & 0.346 & 2.17 \\
JD-4 & 0.013 & 0.0272 & 2.092 & 2.10 & 0.415 & 2.61 \\
JD-5 & 0.013 & 0.0271 & 2.085 & 2.09 & 0.401 & 2.52 \\
\hline
\end{tabular}

Table 5 shows that, the story drift ductility index $\mu$ fluctuates between 1.86 and 2.33 , except for the $\mu$ of JD-1 is all greater than 2. Five models' elastic-plastic of story drift angle $\theta_{\mathrm{u}}$ is between 0.0268 and 0.0359 , only JD-3 meets the requirement of FEMA 267 [5], its $\theta_{\mathrm{u}}$ is exceeding $0.03 \mathrm{rad}$. Since the JD-3 without vertical stiffener to strengthen, the joint region showed a greater flexibility under strong axis impact. And because the position of plastic hinge of the standard beam-column joints formed close to the skin panels, which has constrained the rotation of the beam, leading that the elastic-plastic ultimate angle of other models does not meet the requirements, close to $0.027 \mathrm{rad}$. The viscous damping coefficient $h_{\mathrm{e}}$ of each model are from 0.346 to 0.425 . It has shown that all the models have good energy dissipation ability. Index $h_{\mathrm{e}}$ of the model of welded vertical stiffener compared with no vertical stiffener increased by nearly $15 \%$ and their curves are presented fusiform shaped.

Distribution of the Stress across the Weld at Flange of Beam. The weld in the beam-column connection is the key part of force transmission. And it is the relatively weak part because of the weld defects and residual stress. Historical earthquake disasters shows that the damage for bolted and welded connection at the weak axis is often caused by the brittle fracture of weld. FEMA-355D [6] and other researches points out that the stress distribution on butt weld of h-shaped beam-column connections at strong axis direction is small in the two ends and big in the middle. The weld's equivalent Mises stress of JD-3 and JD-5 at weak axis direction, which under different load cyclic level is shown in Fig. 7.

The load level of each specimens when the local buckling occurred is as follows: JD-3: $\theta_{\mathrm{u}} / \theta_{\mathrm{y}}=2.393, \mathrm{JD}-5: \theta_{\mathrm{u}} / \theta_{\mathrm{y}}=2.085$, and on this basis to divide local buckling into pre-buckling stage and post-buckling stage. The sooner the local buckling occurred, the influence on the weld of stress 
distribution and the ultimate bearing capacity is greater. With the plastic hinge formed gradually, the welding stress at the beam flange becomes non-uniform. So this paper is only discussed the pre-buckling stage.

Figure 7 shows that, the vertical stiffener in the connection of weak axis can ameliorate the distribution of weld stress to a certain extent, making the distribution of stress tends to the ideal W-type. But the standard beam-column joints did not make the plastic hinge away from the skin panel, the buckling and torsional deformation of beam flange could significantly increase the weld stress on one end. Eventually the weld began to be torn from this direction, leading to brittle failure. The weld stress distribution of JD-3 is shown as adverse and flat V-type. Compared with the first load step, the stress of the weld edge can be reduced effectively by $10 \%$. Using the first three loading step can approximately calculate that the stress of the weld edge can be reduced by $4 \%-6 \%$, and the weld stress nephogram is shown in Fig.8.

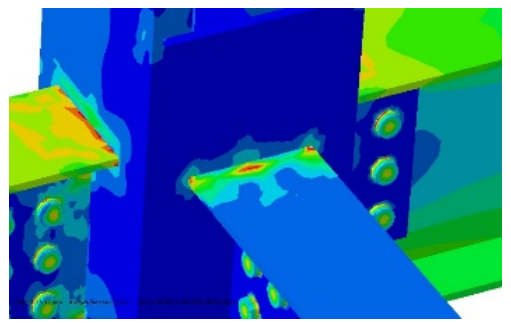

(a) Vertical Stiffener

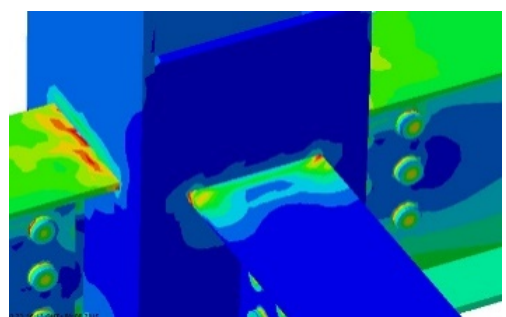

(b) No Vertical Stiffener

Fig.8 Weld stress nephogram

\section{Conclusions and Suggestions}

By the finite element simulation of five models, the mechanical properties of the vertical stiffener have been analyzed and drawn the following conclusions.

(1) According to the simulation results of JD-1 and JD-2, after welded the vertical stiffener, the rigidity of joint region increased by $7 \%$ to $11 \%$, and meet the requirements of the energy dissipation, shown in Fig.6 (a).

(2) Based on the hysteretic curve of JD-4 and JD-5, shown in Fig.5 (d, e), and contrast their energy dissipation coefficient $E$. We found that the addition of vertical stiffener and reducing the thickness of skin panels appropriately has little impact on the ultimate bearing capacity, and the energy dissipation capacity will be reduced only by $3.4 \%$. Considering the $\mathrm{Z}$ direction property of steel plate, the thickness of skin panel should be not less than $10 \mathrm{~mm}$.

(3) From the distribution of the stress across the weld at flange of beam we can see that the vertical stiffener can effectively reduce the bond of weld stress by $4 \%$ to $6 \%$, undermine the prospects of the weld seam pulled crack from one side in an earthquake, and protect joint region effectively.

(4) Shifting plastic hinge away from the skin panel that can relieve torsional buckling effect on the stress distribution in the weld at flange of beam, the new beam-to-column connections welded vertical stiffener combined with RBS(reduce beam section), haunch or beam flange cover plates are recommended. So the weak axis can also show excellent seismic performance, reduce the likelihood of brittle failure of the joint region, and give full play to the advantages of steel structure.

(5) There are some suggestions on processed samples: To separate the transverse stiffeners centered at the vertical stiffener, then weld the transverse stiffeners and vertical stiffener on the column, and use the skin panels to cover and weld.

\section{References}

[1] Seismic Design Code for Buildings (GB50011-2010), In Chinese.

[2] Chengcheng Li: Experimental Research on Reduced Beam Section of Box Strengthen-joint Region Connection for Weak Axis of I-section Column, Chang'an University (2015), In Chinese. 
[3] Peng Wang: Experimental evaluation of flange-plate-reinforced and cover-plate-reinforced steel moment-resisting connections, Qingdao Technological University (2009), In Chinese.

[4] Akio Syokou, Experimental Study of Structure Recovery Characteristics [A], the Japanese Architectural Society [C], Showa 39 years, In Japanese.

[5] FEMA267A,Interim guidelines:Evaluation,repair, modifieation and design of steel moment frames[R]. Calif : SAC Joint Venture, 1997.

[6] FEMA335D. State of the Art Report on Connection Performance. Federal Emergency Management Agency, 2000.

[7] FEMA273. NEHRP commentary on the guidelines for the seismic rehabilitation of buildings[R]. Washington D. C.: Federal Emergency Management Agency, 1997.

[8] Xin Cheng, Yiyi Chen: Moment Resistance of H-section Steel Members Bent About Minor Axis, Journal of Tongji University (Natural Science), 2014,42(1), In Chinese.

[9] Linfeng Lu, Tianhua Zhou, Tao Li: Connection Joint and Connection Method of H-Shaped Steel Beam and Column in Weak Axis, 2009100225682, 2009-10-14, In Chinese.

[10] Aktas M., Earls C.. Minor Axis Moment-Thrust Response Behavior in Steel I-Shaped Members[J]. Journal of Structural Engineering, 2006, 132(7): 1079-1086.

[11] Wenlong Shi, Guoqiang Li, Yong Xiao:, Journal of Building Structure, 2008, 29(5):57-66, In Chinese. 